\title{
TEORIAS DE DESENVOLVIMENTO ECONOMICO: PROBLEMAS METODOLOGICOS
}

JOSÉ PASTORE:

"Portanto... nenhum conhecimento precede a experiência e todos principiam com a experiência." E. KANT.

INTRODUÇĀO

FRANK KNIGHT afirmou que a tentativa de elaborar ou validar teorias no campo da ciência econômica através de observações empíricas era tarefa vã porque "tôdas as ciências sociais são empíricas ... mas os princípios da economia são conhecidos intuitivamente...".

O objetivo dêsse artigo é refutar a posição de F. KNIGHT e demonstrar que, pelo menos na área do desenvolvimento econômico, as "teorias" existentes são de pouca valia quando se pretende utilizá-las como instrumentos para previsão precisamente porque a indução e a investigação empírica têm sido negligenciadas ou não têm sido combinadas de forma adequada com os procedimentos dedutivos correspondentes. Portanto, parafraseando KNIGHT, estamo-nos lançando numa "tarefa vã".

As teorias de desenvolvimento econômico tendem a relacionar um composto de diversos parâmetros através de silogismos lógicos. Todavia, sabemos que as "teorias" existentes não explicam de maneira satisfatória porque um país $X$ se desenvolveu e o país $Y$ permanece economica-

* José PASTORE - Instrutor da Cadeira de Estatística Aplicada da Faculdade de Filosofia, Ciências e Letras da Universidade de São Paulo.

1) F. KNIGHT, Economics and Anthropology, Journal of Political Economy, Vol. 49, 1941, págs. 511 e 512 . 
mente estagnado. Por isso encontramos o lamento constante dos responsáveis pela elaboração de diretrizes de que a feitura de planos para o desenvolvimento não pode basear-se totalmente nas referidas "teorias", pois estas não se adaptam adequadamente às condições específicas de vários sistemas sociais. Observam a propósito que as "teorias" de desenvolvimento econômica são dotadas de pequeno valor explicativo e oferecem poucas possibilidades de previsão, sendo conseqüentemente de aplicação mais do que problemática.

Não são apenas os responsáveis pela elaboração das diretrizes e os planejadores mas os próprios economistas que reconhecem em primeiro lugar, que as teorias são dotadas de reduzida capacidade de previsão, apesar do grande esfôrço para descobrir as causas do crescimento econômico em nossos dias. ${ }^{2}$

Reconhecemos que teorias de baixo poder de previsão dos eventos não constituem monopólio da economia, mas são comuns a tôdas as demais ciências sociais. Porém, neste artigo focalizaremos o problema específico que nos parece mais agudo no processo de teorização, na área do desenvolvimento econômico. Mais modestamente, nos concentraremos em três problemas básicos da formação de teorias sôbre o desenvolvimento econômico: 1) problemas de definição do quantificador universal e constância dos demais fatôres (coeteris paribus); 2) problemas relativos à elaboração de relações de tipo causal; 3 ) problemas relacionados com os métodos de verificação.

O QUANTIFICADOR UNIVERSAL E A CONSTÂNCIA DOS DEMAIS FATORES (COETERIS PARIBUS)

Se bem que as proposições teóricas possam ser expressas sob diversas formas verbais, os metodólogos afirmam que tôdas as proposições científicas são, intrìnsecamente, "con-

2) G. GARB, "The Problem of Causality in Economics", Kyklos, Vol. XVII, 1064. Dáa. 595. 
dicionais genéricas" que podem ser representadas sob a simples formulação: "Para todo $\mathrm{X}$, se $\mathrm{X}$ é $a$, então $\mathrm{X}$ é $b$. ."

A cláusula intrcđuzida pelo conectivo se é conhecida como antecedente, e a cláusula introduzida por então é conseçüente. O prefixo "Para todo X" é o quantificador universal, expressando os limites dentro dos quais a conexão entre $a$ e $b$ é válida. Atrás desta cláusula explícita encontra-se sempre uma oculta, a da constância dos demais fatôres (coeteris paribus), ou seja, a consideração de que tudos os demais elementos permaneçam constantes.

$\dot{E}$ claro que a formulação indicada no parágrafo anterior é a estrutura mais simples de uma proposição teórica e contém as exigências mínimas de um juízo científico. As formulações mais sofisticadas incluem prefixos, do tipo "incremento" tal como se a aumenta, $b$ também aumentará.

Nesta seção pretendemos nos deter em alguns problemas concernentes à formulação do quantificador universal e à generalidade da cláusula coeteris paribus.

- O quantificador universal é a condição necessária e limitativa para que possam ser analisadas as relações entre $a$ e $b$. Isto significa que nenhuma teoria é "desvinculada" ou um universal isolado. A universalidade e a validade de uma proposição científica se manterão apenas na medida em que as características de $\mathbf{X}$ forem conhecidas, definidas e claramente enunciadas.

A literatura do desenvolvimento econômico é rica de proposições que aparentemente não obedecem às exigências expostas. Oferecemos alguns exemplos, tomados ao acaso, de proposições tiradas da economia:

1)

$\mathrm{X}$ : em qualquer sociedade,

a: se encontramos uma ilimitada disponibilidade de mão-de-obra,

3) E. Nagel, The Structure of the Science, Nova Iorque: Harcourt Brace and Company, 1961, pág. 47. 
b: então teremos aumentos nos lucros e na taxa de acumulação de capital. ${ }^{4}$

$\mathrm{X}$ : Em qualquer sociedade,

a: se existir talento empresarial,

b: então, assistiremos ao desenvolvimento econômico. ${ }^{5}$

3)

$\mathrm{X}$ : Em qualquer sociedade,

a: se houver um aumento em $s$ (poupança) e em $p$ (relação capital-produto), dado $r$ (taxa de eficiência marginal do capital),

b: então, teremos um aumento na taxa de crescimento. ${ }^{6}$

Até que ponto estas proposições e outras do mesmo tipo, constituem "teorias científicas"? Antes de entrarmos na discussão do problema, caracterizaremos uma "proposição científica" nos limites da cláusula da constância dos demais fatôres (coeteris paribus).

- A enumeração completa de tôdas as condições e características do quantificador universal dentro das quais a e $b$ ocorrem é dificultada por muitas barreiras de natureza prática e conceitual. Mesmo nas ciências físicas a cláusula da constância dos demais fatôres (coeteris paribuss) é raramente verificada de maneira absoluta. Os fenômenos empíricos sempre ocorrem de maneira estreitamente relacionada, nunca isoladamente, e isto é particularmente verdade do mundo social. A cadeia de variáveis e de relações é portanto inumerável.

4) W. A. LEWIS, "Economic Development with Unlimited Supplies of Labour", in A. N. Agarawla e S. P. Singh, The Economics of Underdevelopment, Nova Iorque: Oxford University Press, 1963, pág. 418.

5) E. E. HageN, On the Theory of Social Change, New Jersey: Dorsey Press, 1962.

6) H. W. SINGer, "The Mechanics of Development" in A. N. Agarawla e S. P. Singh, op. cit., pág. 396. 
A impossibilidade do cientista manusear tôdas estas relações ao mesmo tempo exige eliminações arbitrárias na realidade (para que se possa especificar X) e para permitir o estudo dos fenômenos que têm lugar dentro da área arbitràriamente determinada. Desta maneira o cientista opera apoiado em duas hipóteses bastante ousadas: de que a "eliminação", apesar de arbitrária, mantém as características essenciais da realidade e que dentro da área selecionada existem algumas variáveis independentes que permanecem constantes, enquanto as variáveis dependentes se modificam.

Contudo, a arbitrariedade destas hipóteses é habitualmente atenuada pela intrcdução de descrições das características daquela parte da realidade que foi "eliminada", ou seja, X.

Agora, estamos em corıdições de reformular a questão levantada anteriormente até que ponto as proposições da ciência econômica sôbre desenvolvimento econômico constituem realmente teorias ou sistemas de teorias? Primeiramente, deve-se notar que os parâmetros envolvidos no quantificador universal (X) são raramente explicitados nas teorias do desenvolvimento econômico. "Sociedade humana", "economia", "sistema econômico" são geralmente um $\mathrm{X}$ oculto nas teorias existentes. Pelo fato de Singer não especificar que tipo de $\mathbf{X}$ é considerado em sua teoria, pode-se inferir um quantificador universal bastante genérico, como qualquer sociedade. A partir daí surge o problema de que fatôres de $\mathrm{X}$ devem ser considerados constantes para que se possam prever as relações entre $a$ e $b$ ? SiNGER provàvelmente responderia: não há necessidade de caracterização de $\mathrm{X}$, pois pressupõem-se um coeteris paribus ampla ou seja, "todos os demais fatôres permanecem constantes". Mas o maior problema com uma coeteris paribus tão amplo é que quanto maior fôr o número de variáveis presentes, maior será também a probabilidade de suas variações e menor o poder explicativo da teoria. E plenamente justificado que se espere uma variação maior de 1000 variáveis do que de 10 . Em outras palavras, se fôr pressuposto um número infinito ou desconhecido de variá- 
veis na coeteris paribus, surge a obrigatoriedade de admitirse ser pouco improvável que um número infinito de variáveis se mantenha sempre constante. Se tal fôr c caso, as relações entre $a$ e $b$ não serão mais válidas e não se terá chegado a nenhuma teoria.

A crítica dirigida às teorias econômicas não é de forma alguma nova. Desde 1930 até 1950 os antropólogos e sociólogos têm afirmado que as leis gerais da economia estavam baseadas em pressupostos como o "homem racional", a "maximização dos lucros", etc. que não eram válidos para qualquer sociedade, nem mesmo nas consideradas sociedades onde predomina uma economia de mercado. Em nossos dias a culpa imputada aos economistas adquiriu um caráter mais refinado, porém no fundo é a mesma. Os próprios economistas reconheceram recentemente as limitações envolvidas na utilização de um quantificador universal extremamente amplo, afirmando que os modelos econômicos só poderiam ser transferidos para sistemas sociais diversos daqueles em que haviam sido elaborados após reformulação. Apesar desta "autocrítica" não temos assistido a grandes esforços para limitar a extensão do quantificador universal ou para tornar mais claras suas implicações no processo de elaboração de teorias sôbre desenvolvimento econômico.

\section{AS RELAÇôES DE CAUSALIDADE NAS TEORIAS DE DESENVOLVIMENTO ECONOMICO}

O problema da causalidade ainda constitui uma questão aberta no campo da economia. Há também economistas que, seguindo a posição de DAvid HUME a propósito da causalidade - isto é, de que a causalidade é simples atributo mental sem correspondência na realidade exterior à inteligência - deixam de reconhecer a importância das proposições causais para que suas teorias permitam prever as etapas posteriores do processo; e dentre êles FRIEDMAN surge como o mais importante representante. ${ }^{7}$

7) M. FrIEDMan, "The Methodology of Positive Economics" in Essays in Positive Economics, Chicago: The University of Chicago Press, 1953. 
Isto, todavia, não serve para negar o fato de que a maioria dos economistas ainda trate os problemas de forma explícita ou não, através de proposições do tipo causal, seguindo a tradição dos melhores economistas clássicos. JoHN STUART MiLl disse ser "o objetivo da economia política a busca das causas que governam a produção e a distribuição da riqueza". Desta forma a questão fundamental das ciências sociais será "descobrir as leis segundo as quais a situação da sociedade num determinado momento produz o estado que lhe é posterior e o substitui". ${ }^{\text {A A }}$ mesma tendência pode ser encontrada entre outros economistas como KaRL MARX, ADAM SMITH e DAVID RICARDO, embora por razões diversas. Os teóricos moldernos como Wold, Simon, OCCURT, Singer, Fourastí́ e CELso FuRTAdo têm dedicado grandes esforços a fim de esclarecer o conceito de causalidade na análise econômica. As teorias de desenvolvimento econômico, mais do que ot tros campcs científicos, são particularmente permeadas pelo conceito de causalidade. ARTHUR LEWIS diz claramente que há três causas "próximas" do desenvolvimento: o esfôrço para poupar; o aumento do conhecimento e sua aplicação; bem como, o aumento de capital e outros recursos per capita. ${ }^{10}$ Porém, o ponto crucial está em explicar quais os fatôres responsáveis pelo desenvolvimento de uma nação, ou mais precisamente, quais as causas do desenvolvimento.

BenJAmin Higgins observa que "a tarefa fundamental da análise eccnômica do problema do desenvolvimento é descobrir quais dos círculos viciosos são os causadores dos demais, e que deverão ser prontamente rompitos, bem como, os que podem ser convertidcs em mecanismos realimentadores (feedback mechanisms) provocando o crescimento contínuo (sustained growth). ${ }^{11}$

\footnotetext{
8) J. S. Mill, Principles of Political Economy, Londres: Longmans, Green, 1920, pág. 1 .

9) J. S. MILl, A System of Logic, Londres: Longmans, Green, 1900, pág. 295.

10) W. A. LEwis, The Theory of Economic Growth, Homewood: Richard D. Irwin, 1955, pág. 1 .

11) B. Higgins, Economic Development, Nova Iorque: Norton and Co., 1959, pág. 24.
} 
Parafraseando MACIVER poderíamos dizer que qualquer que seja a diferença na taxa de crescimento de um país, existirão diferenças nos fatôres responsáveis por essa mesma taxa. ${ }^{12}$ Resumidamente, todo evento tem uma causa e não é possível prever acontecimentos futuros se os fatôres que os produzem permanecerem desconhecidos. Estamos aqui admitindo explìcitamente que lidar com proposições do tipo causal é condição necessária para podermos elaborar teorias realmente explicativas da realidade.

Quais são as exigências fundamentais dos modelos causais, e em que medida as teorias de desenvolvimento baseadas no conceito de causalidade satisfazem estas exigências?

BURGE aponta que o elemento essencial no conceito científico de causa é a idéia de produção. ${ }^{13}$ Quando afirmamos que $X$ é a causa de $Y$, temos presente em nossa mente que uma mudança em $\mathrm{X}$ produz uma mudança em $\mathrm{Y}$ e não que uma mudança em $X$ é seguida ou está associada a uma modificação em $\mathrm{Y}^{14} \mathrm{Na}$ verdade tal concepção da causalidade tem sua origem numa idéia de bom-senso: "a causa é o que faz com que uma coisa aconteça". ${ }^{15}$ Mas quando SINGER afirma que "o aumento na taxa de poupança líquida do índice capital-renda produz maior desenvolvimento econômico, mantida constante a taxa de crescimento da população", êle está, pelo menos implìcitamente, aceitando a idéia de causalidade. Até que ponto a relação apontada é uma medida válida da qualidade produtora de uma causa?

Uma análise detida do modêlo de SINGER revela que está inteiramente baseado na equação $D=s p-t$, ou seja, numa 1elação absolutamente simétrica e irreversível que pode ser interpretada de duas maneiras, o que acaba sendo feito

12) R. M. MAciver, Social Causation, Nova Iorque: Ginn, Press, 1942, págs. 1 a 21.

13) M. Burge, Causality, Cambridge: Harvard University Press, 1949, págs. 46 a 48 .

14) H. H. Blalock, Causal Inferences in Non-Experimental Restarch, Chapel Hill: University of North Carolina Press, 1964, pág. 9.

15) S. L. Stebring, Moder Logic, Nova Iorque: Torche Books, 1961, pág. 260 . 
pelo próprio Singer. Desta forma a equação que de acôrdo com o autor em questão prcporciona um grande esclarecimento sôbre o mecanismo do desenvolvimento não pode ser utilizada como uma proposição explicativa de tipo causal, uma vez que a qualidade produtora das proposições causais pode ser encontrada apenas em relações assimétricas. $O$ modêlo de Singer deve ser considerado apenas como uma definição de desenvolvimento econômico e não como um sistema explicativo do mecanismo de desenvolvimentc. Sob êste aspecto, a fórmula de SiNGER aparece como uma verdadeira tautologia e não como uma semitautologia, como o próprio autor parece reconhecer. Embcra concordemos que as tautologias são importantes para o processo de elaboração de conceitos, elas tornam-se inúteis como fundamento para proposições explicativas.

Esta crítica pode ser estendida a outros economistas que baseiam suas formulações apenas em "conjunção constante". Se bem que esta possa ser uma parte da causalidade, a conjunção por si mesma, não é suficiente para que se distinga uma relação causal de outros tipos de associação. Sugerimos que o economista opte pelo abandono implícito cu explícito do estilo causal de suas generalizações sôbre o desenvolvimento econômico ou melhore a sua estratégia metodológica para poder atingir a explicação de tipo causal.

Parte da obscuridade das teorias econômicas modernas tem sua origem na falta de precisão com que se definem as classes de variáveis discutidas no tópico sôbre o Quantificador Universal e a Constância dos Demais Fatôres. Uma teoria explicativa de tipo causal deverá conter pelo menos quatro tipos diversos de variáveis.

Variáveis independentes ou dependentes: são as que interessam diretamente ao economista e que são passíveis de manipulação. Exemplificando: sendo o desenvolvimento econômico a variável dependente, serão variáveis independentes a taxa de crescimento da população, a taxa de poupança, a taxa de investimento em bens de capital, a 
taxa de investimento em recursos humanos, o índice imput-output, etc.

- Causas potenciais: são as variáveis que exercem influência causal nos fenômenos em cbservação mas não variam durante a observação da variável dependente. Exemplificando: a taxa de inovação empresarial (entrepreneurship), a estabilidade política da sociedade, etc., podem ser fontes importantes de alterações nas variáveis dependentes $\mathrm{e} / \mathrm{ou}$ independentes.

A terceira classe de variáveis é constituída por tôdas aquelas que não estão sob ccntrôle e são responsáveis por modificações nas variáveis dependentes durante o período de observação, mas que são irrelevantes para as variáveis explicativas. Exemplificando: o preço de produtos agrícolas no mercado internacional pode ser uma variável não diretamente relacionada às variáveis explicativas tais como a taxa de crescimento da população, que pode desempenhar papel importante na determinação do desenvolvimentc econômico de um país.

- A quarta classe de variáveis inclui aquelas cujos efeitos estão, embora de maneira desconhecida, sistemàticamente relacionados às variáveis explicativas. As influências das variáveis desconhecidas confundirão os efeitos produzidos pelas variáveis explicativas. Exemplificando: o treinamentc no local de trabalho (in service training) pcde ser confundido com o aumento na taxa de investimento em recursos humanos.

A primeira classe de variáveis pode ser controlada pela própria estruturação que se der à análise. Todavia, o contrôle dos outros tipos de variáveis exigirá: 1) que o "sistema fechado" de variáveis escolhido com $\mathrm{X}$ realmente contenha as dimensões causais fundamentais; 2) um conhecimento geral das variáveis circundantes do sistema; 3 ) e finalmente um conhecimento geral da natureza e da composição de cada variável explicativa e das possiveis variáveis correlatas.

O trabalho com tipcs diferentes de variáveis ou mesmo o seu simples enunciado são acontecimentos raros nas teo- 
rias sôbre desenvolvimento econômico. A ausência de atividade interdisciplinar constitui sério fator que impede a satisfação da segunda e da terceira condição que acabamos de mencionar. Uma estrutura rigcrosa, para que se procedam às especulações, é ainda hoje negligenciada na área do desenvolvimnto econômico e como conseqüência as teorias tendem a ser "válidas" apenas no âmbito de realidades não empíricas. LEWIS sugere que em certas circunstâncias a inflação pode ser utilizada para financiamento do desenvolvimento desde que ela pcssa ser reabsorvida. ${ }^{16}$ Porém, o poder explicativo desta proposião reduz-se dràsticamente quando outras dimensões necessárias são introduzidas em seu modêlo do que parece ter-se apercebido Myint, quando menciona dimensões extra-econômicas dos processos inflacionários. Nas economias inflacionárias "tão $\log$ o se cria a expectativa da alta de preços, surge um fator inibidor da poupança", o que equivale a afirmar que a inflação não será reabsorvida, isto porque a incerteza psicológica, a instabilidade política e a tensão social constituem componentes inevitáveis da síndrome inflacionária. $\mathrm{Na}$ verdade, tcdos êstes fatôres tendem a compensar e/ou neutralizar os eventuais efeitos positivos da inflação. Portanto, certas circunstâncias apontadas por LEWIS raramente serão válidas em $\mathrm{X}$, e se isto é verdade podemos concluir pela inutilidade de seu modêlo. Talvez seja válido apenas ccmo um "tipo ideal" a ser atingido através de diretrizes econômicas, mas tal aspecto ultrapassa os limites dêste artigo.

Convém observar, a esta altura, que não aceitamos a idéia de que o desenvolvimento econômico, enquanto objeto de especulação científica, constitui um "composto econômico", mas sim uma constelação complexa de fatôres econômicos e não-econômicos. Assim, a utilização de "leis gerais" não empíricas, pode não ser adequada ao estudo dos fenômenos que não seguem uma sequiência racional e lógica. Concordamos plenamente com SchoEfler que diz serem os

16) H. MYinT, The Economies of the Developing Countries, Nova Iorque: Praeger, 1965, pág. 145. 
progressos das tıorias sôbre desenvolvimento econômico tão lentos e penosos, porque os modelos, conceitos e instrumentos de análise empregados pelos economistas são fundamentalmente incompatíveis com o objeto de estudo. ${ }^{17}$ Isto equivale a dizer que "os economistas têm de aceitar o fato de que uma atividade econômica tem lugar numa estrutura orgânica na quial tôdas as partes estão ìntimamente relacionadas, influenciam-se mùtuamente e são interdependentes...". ${ }^{18}$

PROBLEMAS DE VEIRIFICAÇÃO EM TEORIA DE DESENVOLVIMENTO ECONÔMICO

Todo cientista é obrigado a satisfazer as exigências da possibilidade da verificação, quando apresenta proposições gerais sôbre um fenômeno como um conjunto dedutivo de afirmações. $O$ processo de verificação do conhecimento científico envolve várics problemas. Todavia, nos restringiremos ao exame de dois tipos fundamentais de problemas que têm lugar no processo de elaboração de teorias sôbre o desenvolvimento econômico ou seja, os que dizem respeito à adequação das técnicas de verificação e aos problemas de mensuração.

Técnicas de Verificação - Entendemos por verificação o procedimento ou conjunto de procedimentos elaborados para descobrir se os dados referentes a uma situação real são adequados ao conjunto de generalizações sôbre a referida situação ou sôbre um tipo ideal de situações reais que incluam a primeira. ${ }^{19}$

Em economia, acreditamos serem possíveis três posições diversas no que diz respeito à questão da verificação.

- Os "aprioristas" que defendem a posição de que a eccnomia é um sistema a priori de verdades, um produto da

17) S. Schonffler, The Failures of Economics, Cambridge: Harvatd University Press, 1955. Provê bibliografia pràticamente completa sôbre problemas de metodolcgia econômica. Vide especialmente págs. 209 a 245.

18) W. I. GReENWALD, "Common Irrelevances in Contemporary Theorizing by Economists" in Kyklos, Vol. 10, 1957, págs. 302 a 315.

19) F.MACMLUP, "The Problem of Verification in Economics", in Southern Economic Journal, Vol. 22, 1955, págs. 1 a 21. 
razão, uma ciência, "não sujeita à verificação ou à refutacão com base na experiência"," "uma ciência exata que aÍcança leis tão universais como a matemática"," "um sistema te deduçóes a partir de uma série de postulados". ${ }^{2}$ Fortanto, qualquer verificação, se necessária, terá de ser realizada apenas ao nível da lógica formal. ${ }^{23}$

- A seguir, temos os "ultra-empíricos" que afirmam serem "os pressupostcs fundamentais da economia imaginários, não verificáveis e irreais. . . e que... as investigações deveriam principiar pelos fatos e não por pressupostos"... ${ }^{24}$

- Entre estas duas posições extremadas existe uma "tendência composta" que, evidentemente, insiste numa verificação do tipo empírico-dedutivo. Esta posição por sua vez se subdivide em duas ramificações com economistas como Machlup que enfatizam os processos "indutivo-dedutivcs" enquanto outros, dentre êles LANGE, enfatizam o procedimento do tipo "dedutivo-indutivo".

De qualquer forma os economistas contemporâneos concordariam ser a coerência lógica, condição necessária mas não suficiente para a validade da verificação das teorias elaboradas. As teorias sôbre o desenvolvimento econômico parece, contudo, ter conseguido atingir, em grande parte, as exigências da coerência lógica, mas não as exigências da coerência empírica. Embora exagerando, GoRDON afirma que as teoriàs de desenvolvimento econômico são formalmente válidas, mas inúteis. ${ }^{25}$

20) L. Von Miese, Human Action: A Treatise on Economics, New Haven: Yale University Press, 1949, pág. 858.

21) F. KNIGHT, "The Limitations of Scientific Method in Economics", in R. G. Tugwell, Ed., The Trend of Economics, Nova Iorque: Appleton Century Crafts, 1930, pág. 256.

22) L. RoBins, An Essay on the Nature and Significance of Economic Science, Londres: McMillan, 1935, pág. 99.

23) K. H. PARSONs, "The Logical Foundations of Economic Research" in Journal of Farm Economics, Vol. 31, 1949, pág. 661.

24) T. W. Hutchison, The Significance and Basic Postulares of Economic Theory, Londres: McMillan, 1938, pág. 166.

25) D. F. GORDON, "Operational Propositions in Economic Theory in The Journal of Political Economy, Vol. 62, 1955, págs. 150 a 161. 
Atentando para o problema das técricas empíricas de verificação para a elaboração de teorias do desenvolvimento, e examinando as tecrias existentes, tentaremos ver até que ponto elas são passíveis de um rigoroso processo de verificação empírica.

No estado atual do conhecimento, duas técnicas de verificação empírica parecem ser usadas "intuitivamente" na área do desenvolvimento econômicc: a ex-post-facto e a da análise comparativa. Inicialmente, poderíamos observar que estas duas técnicas não são mùtuamente exclusivas, a última podendo ser considerada uma variação da primeira.

A técnica ex-post-facto tenta verificar se um conjunto de eventos, ou se c conjunto das características do desenvolvimento econômicc está causalmente relacionado, e qual a extensão dêste relacionamento no sentido de provocar modificações num dado sistema. ${ }^{26}$ Os especialistas em metodologia parecem concordar que as verificações ex-post-facto satisfazem de maneira geral as exigências para o contrôle da pesquisa empírica, mas apresentam alguns problemas. $\mathrm{Na}$ área específica do desenvolvimento econômico os problemas principais são:

1) Os que dizem respeito: à identificação e definição das variáveis explicativas relevantes; à seleção de dados para uma amostragem significativa, ao encontro de dados que permitam uma inferência confiável a ser extraída das comparações ou de várias classes de dados da amostra etc. Nossa opinião é que nenhum dos problemas foram resolvidos pelos teóricos do desenvolvimento e nem sequer devidamente enfrentados. Um levantamento da bibliografia utilizada não demonstrou um único trabalho sôbre desenvolvimento econômico que incluísse um capítulo sôbre os problemas e a metodologia das verificações. Assim nunca sabemos que variáveis ou indicadores devem ser selecionados para verificar a validade empírica de uma teoria. Também se ignora quantos e que tipos de sistemas

26) E. NAGEL, op. cits., pág. 457. 
deveriam ser considerados para verificação do conhecimento teórico existente no campo do conhecimento econômico.

2) Outro problema crucial é o relativo à natureza da evidência necessária para que se possa conceder uma significância válida às correlações existentes entre os dados. A sofisticação estatística dos economistas modernos são seguros indicadores de estarem atentos ao fato de que estas correlações não significam obrigatòriamente a existência de causalidade. Porém, como já indicamos anteriormente, isto não parece ocorrer quando os teóricos trabalham na área do desenvolvimento econômico. A conjunção e as ilustrações conccmitantes são freqüentemente usadas como "testes empíricos" para a validação de teorias. O problema real é que, não se estabelecendo um critério evidente a respeito dos dados necessários para validar uma teoria, poderá dizer-se que as "reconstruções" existentes servem apenas como ilustrações e não como verificações. Neste sentido a teoria de Rostow é um bom exemplo. O referido autor levanta em sua obra uma questão teórica extremamente pertinente, isto é, “. . . como se explica que alguns sistemas econômicos tenham abandonado a estagnação ... e partido para uma situação em que o crescimento passou a ser a condição econômica normal?". ${ }^{27} \mathrm{~A}$ resposta de Rostow é que a "decolagem" (take-off) é o renômeno crucial na realização do desenvolvimento econômico a curto prazo em muitos países. As evidências "verificáveis" desta proposição são obtidas de estudos de casos como a Suécia, o Canadá etc. Porém, o material estatístico apresentado não assegura evidência de que a "decolagem" (take-off) seja um precedente ou uma causa relativamente isolada do desenvolvimento econômico. $\mathrm{Na}$ verdade, poder-se-ia afirmar que a "decolagem" (take-off) poderia ser utilizada perfeitamente como definição do processo de desenvolvimento econômico em si. Como observa Hirschman, atribuir uma função causal aos acontecimen-

27) W. W. Rostow, "The Take-Off into Self-Sustained Gorwth" in $A . N$. Agarwala e S. P. Singh, op, cit., pág. 156. 
tos passados, exige que, entre outras coisas, se especifique em que "quantidade" a condição em questão estêve presente no desencadeamento do processo. ${ }^{28}$

KUTZNETS compara as características dos países avançados econômicamente no estágio anterior à "decolagem" (take-off) com os países subdesenvolvidos contemporâneos. Embora mostre algumas diferenças interessantes, particularmente no que se refere às tendências populacicnais, sua análise reduz-se a uma descrição, pois não são estabelecidos vínculos de causalidade entre os fenômenos. ${ }^{29}$ estabelecidos vinculos de causalidade entre os fenô?

Resumindo, estamos tentando demonstrar que não existem razões a priori que fazem a abordagem histórica inútil ao entendimento do prccesso de desenvolvimento econômico. Mas para que a história econômica contribua de maneira positiva, ela deve conter mais do que simples descrições ou ilustrações do que aconteceu no momento em que as nações, hoje desenvolvidas, começaram o seu processo de desenvolvimento. ". . . A descrição (do processo de desenvolvimento econômico) que nos diz o que aconteceu, da mesma forma que se descreve o processo de crescimento dos indivíduos, acaba por excluir a importante questão da causa da ocorrência das mudanças." ${ }^{30}$ Os historiadores de economia têm realizado trabalho essencialmente cronológico, com pequeníssima análise histórica; sabendo-se que a cronologia não pode fornecer mais do que descriçõ̃es, permanece a lacuna das explicações.

3) Outro problema importante é o da estrutura da investigação. A que melhor se presta à validação externa é evidentemente aquela que se faz sob forma de experimentação controlada na qual um programa de desenvolvimento seria construído com base em hipóteses, e pos-

28) A. O. Hirschman, "Obstacles to Development: A Classification and a Quasi-Vanishing Act", in Economic Development and Cultural Change, Vol. 13, 1965, págs. 385 a 393 .

29) S. Kutznets, "Underdeveloped Countries and the Pre-Industrial Phase in the Advanced Countries: an Attempt at Comparison", (1954) in A. N. Agarwala e S. P. Singh, op. cit., págs. 135 a 153.

30) S. ENKE, Economics for Development, New Jersey: Prentice Hall, 1964, pág. 190 . 
teriormente implementada e julgada. Entretanto, tal tipo de estruturação não é factivel para os problemas do desenvolvimento devido limitações óbvias. Por isso o recurso mais accessível para a validação empírica consiste na introdução de generalizações parciais de uma teoria ou conjunto de teorias nas diretrizes econômicas. Aqui, novamente, surge $c$ problema de saber-se até que ponto as "generalizações parciais" são representativas da doutrina como um todo. As diretrizes mistas parecem denotar objetivos conflitantes e/ou mùtuamente exclusivos. EISENSTADT observa que as diretrizes introduzidas pelos colonialistas nas áreas subdesenvolvidas são de natureza contraditória. Por um lado, enfatizam as modificações de tipo racional para a economia, a tributação e a administração sistemática. Em oposição exigem lealdade política, obediência passiva e identificação completa que são indisciativelmente sérios obstáculos às modificações que pretendem introduzir.

4) Uma quarta dificuldade para a validação externa surge não ao nível dos procedimentos, mas no domínio da lógica. Há economistas que partem do pressuposto da primazia dc sistema econômico na sociedade. CELso FuRTADO diz que as "inovações tecnológicas, que constituem a essência do desenvolvimento econômico, não apenas provocam mudanças na estrutura do sistema de produção, ... . mas as modificações na estrutura econômica tendem a introduzir mudanças na estrutura sccial como um todo..."."31 A teoria do "crescimento desequilibrado" (unbalanced growth) de HIRschman baseia-se no mesmo pressuposto.

O teórico que adota a primazia do econômico coloca-se diante de um dilema. Admitamos primeiramente que esta primazia fôsse uma verdade. Seria então necessário reconhecer que a implementação de um plano de desenvolvimento, baseado numa teoria, provocaria atritos e irritações de outros segmentos do sistema. Se êste fôr o caso, o teórico terá de assumir uma posição técnica para distinguir

31) C. Furtado, Dialética do Desenvolvimento, Rio de Janeiro: Ediçóes Fundo de Cultura, 1964, pág. 29. 
até que ponto as reverberações do sistema atingem o plano, introduzindo mudanças nas condições iniciais do modêlo. Inversamente, se o pressuposto de que a primazia do econômico é falsa, não terão lugar modificações em outros segmentos do sistema e será evidente que apesar da definição de desenvolvimento econômico que foi usada, êste não ocorreu e tôda e qualquer possibilidade de validação externa é eliminada.

Ignoramos qualquer esfôrço sistemático que tenha sido realizado para a solução do dilema apontado. Os economistas têm aceitado como evidente o que permanece ccmo matéria obscura para as demais ciências sociais.

Somos forçado a reconhecer que parte da dificuldade encontrada pelos economistas tem sua origem no fato de que as ciências sociais ainda não atingiram um conjunto de conhecimentos, aceitáveis sem maiores discussões, sôbre o funcionamento das relações das várias partes do próprio sistema social. Por outro lado, se insistimos no êrro dos economistas, não nos negamos a reconhecer que os próprios economistas sentem-se incapazes de verificar a validade externa de suas teorias pela falta de conhecimento que deveria ser provido por sociólogos, antropólogos e demais cientistas sociais. Talvez o desenvolvimento, de uma sociologia da história seja uma das tarefas mais urgentes de nossos dias.

Problemas de Mensuração - O segundo grupo de problemas importantes envolvidos no processo de verificação é o da mensuração que na verdade constitui sempre uma fonte de dificuldades para qualquer ciência. Porém, algumas ciências, como é o caso das ciências físicas, conseguiram estabelecer sistemas de contrôle bastante razoáveis, o que não ocorreu com outras ciências, entre as quais listariamos as sociais. Os sistemas de contrôle diminuem os efeitos negativos das distorções do processo de mensuração. Dentre as ciências sociais a economia é, talvez, aquela em que maiores avanços foram realizados no sentido de precisar as técnicas de medição, porém, isto não é verdadeiro para tôdas as áreas da economia. As questões referentes ao de- 
senvolvimento econômico enfrentam graves problemas de medição, semelhantes aos encontradiços em tôdas as outras ciências sociais, e suficientes para ameaçar a validade das generalizações.

Entendemos por validade a extensão correspondente entre um indicador e uma definição. A validade perfeita significa que $o$ indicador tenha o mesmo objetivo e o mesmo conteúdo da definição. ${ }^{32}$ GuTTMAN reconhece no problema da validade dois aspectos: a "validade interna" e a "validade externa". A primeira expressa uma relação de tipo lógico, enquanto a segunda expressa uma relação de tipo lógico, enquanto a segunda outra de tipo empírico, ou seja, com a realidade externa ao sujeito que pensa. ${ }^{33}$

1) Admitamos uma definição de "desenvolvimento econômico", representada por um círculo cheio.

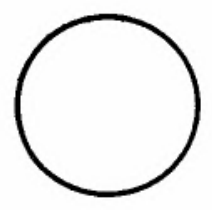

Admitamos também que os indicadores (medidas econômicas sôbre renda nacional, taxa de crescimento populacional, etc.), sejam representados por um círculo pontilhado.

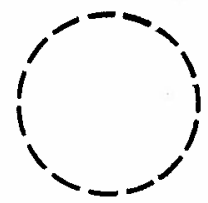

32) H. L. ZETTERBERG, On Theory ard Verification in Sociology, Totowa: The Bedminster Press, 1965, Capitulo 7.

33) L. Guttman, "The Problem of Attitude and Opinion Measurement", in S. A. Stouffer, Measurement and Prediction, New Jersey: Princeton University Press, 1950, págs. 57 a 59 . 
Há vários problemas envolvidos na questão do ajustamento entre os indicadores e a definição. Talvez a mais importante, na área do desenvolvimento econômico, seja que a definição amplie o indicador e acabe por adicionar algo que não está contido no indicador.

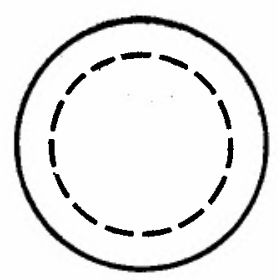

Este seria o caso de utilizar-se o aumento da renda per capita como a definição operacional de desenvolvimento econômico. A definição ultrapassa o que está contido no indicador, pois uma distribuição mais equânime da renda está implícita na definição nominal de desenvolvimento econômico mas êste aspecto não é coberto pelo indicador, que se refere apenas ao aumento da renda per capita em têrmos agregados. Por outro lado, o indicador reflete apenas alguns aspectos do fenômeno como êle é definido. Evidentemente esta não-identidade entre definição e indicador afetará diretamente a validade das generalizações.

2) Com relação ao problema da "validade externa", apesar de já discutida anteriormente, acrescentaríamos que os economistas do desenvolvimento subestimam o problema e suas sérias implicações, como a falta de informações, a inadequação dos dádos disponiveis, etc., para que se possa obter a validação externa das generalizações enunciadas. PAUUW observa que grande parte da pesquisa na área do desenvolvimento econômico enfrenta sérios problemas com relação aos dados, porque os países subdesenvolvidos oferecem poucos dados sôbre sua situação social e econômica, e nem sempre exatos, o que diminui 
bastante a confiança que nêles pode depositar o pesquisador ávido de encontrar fundamento para suas generalizações. ${ }^{34}$

Assistimos a uma limitação prática dos esforços dos teorizadores e também a um uso inadequado dos dados existentes. SeERs afirma que "entre os erros mais comuns cometidos pelos economistas que trabalham em países que não os seus, encontra-se a tentativa de construir com um modêlo excessivamente elaborado, . . . a partir de informação estatística incompleta e, portanto, pouco confiável; mais incompleta, inclusive, do que os economistas treinados em países industrializados possam imaginar... Na verdade, muitos dos mais elegantes modelos, que se têm elaborado para vários países subdesenvolvidos, são pouco mais que fantasias".

Outro problema para a validação externa diz respeito às limitações das medições precisas devidas às reverberações das variáveis quando submetidas a "tratamento econômico". Empresários, consumidores, sindicatos e outros grupos, quando adquirem conhecimento são capazes de modificar, e frequientemente modificam o seu comportamento e o resultado é a mudança dos dados iniciais a ponto de tornar a teoria inaplicável. O efeito do conhecimento ou da aplicação do conhecimento aos dados conduz o teorizador a zituações em que as generalizações não podem ser mais demonstradas, nem contraditadas ${ }^{36} \mathrm{~A}$ melhoria das técnicas de medição, bem como o aperfeiçoamento dos próprios conceitos, constituem a tarefa básica para obter generalizações dotadas de maicr validade.

34) D. S. PAUUW, "Some Frontiers of Empirical Research in Economic Development" in Economic Development and Cultural Change, Vol. 9, 1961, págs. 180 a 190.

35) D. SEERS, "Why Visiting Economists Fail?" In D. E. Noveck e R. Leckachman, Development and Society: The Dynamics of Economic Change, Nova Iorque: St. Martin Press, 1964, pág. 381.

36) M. J. LEVY, "Some Basic Methodological Difficulties in Social Science", in Pholosophy of Science, Vol. 17, 1950, pág. 208. 


\section{CONCLUSÕES}

Utilizamos ao longo dêsse artigo a expressão "teoria científica do desenvolvimento econômico" que significa "um sistema dedutivo empiricamente verificado". ${ }^{37}$ Foi nosso objetivo mostrar que os teóricos do desenvolvimento têm negligenciado sérios problemas metcdológicos, afetando, portanto, a própria validade de suas generalizações.

A despeito da negligência, demonstramos que os economistas tendem a insistir na apresentação de suas generalizações, que se tem caracterizado pela pretensão de se exigirem em sisiemas dotadcs de universalidade, de maneira a não poder ser justificada pela metodologia usada para a aquisição do conhecimento. Observamos uma tendência geral das várias "teorias" sôbre desenvolvimento para as generalizações amplas, apesar dos economistas desconhecerem se as hipóteses fundamentais, utilizadas no "sistema fechado" de variáveis, são válidas para qualquer sistema. Também acentuamos uma tendência para tornar mais fáceis a linguagem, o estilo e os tipos de inferências de modelcs causais embora cs procedimentos não satisfaçam as exigências dos esquemas de causalidade. Também foi notado que os teoristas tentam elaborar sistemas complexos de proposições dedutivas $s \in m$ que se registre um grande esfôrço para o aperfeiçoamento dos métodos de veriiicação do conhecimento existente.

Contudo, partimos do pressuposto de que as teorias dotadas de grande possibilidade explicativa - se tal puder ser conseguido no campo do desenvolvimento econômico - exigem maior rigor na definiçăo do sistema de variáveis contidas no quantificador universal, mais precisão no enunciado das condições en que as variáveis devem ser estudadas, mais conhecimento empírico que possibilite o estabelecimento de relações assimétricas de forma mais

37) F. S. C. Northrop, "The Method and Limited Predictive Power of Classical Economic Science", in The Logic of the Sciences and the Humanities, Nova Iorque: Meridian Books, 1959, pág. 235. 
adequada entre as variáveis, e, finalmente, mais esfôrço para que se possa realizar a verificação lógica e empírica das proposições dedutivas.

Nossa inclinação seria pela conclusão de que a maior parte das teorias existentes não tem satisfeito as exigências que acabamos de enumerar. Conseqüentemente o resultado é que o conhecimento obtido não é simplesmente dotado de pequeno poder explicativo, mas também não pode ser submetido a processos rigorosos de verificação.

É verdade que tôda a crítica contra a teorização sôbre o desenvolvimento econômico pode ser dirigida nos mesmos têrmos contra tôdas as demais ciências sociais. A sociologia, a antropolcgia e a ciência política ainda não foram capazes de apresentar uma teoria exaustiva sôbre a mudança social. Todavia, tais argumentos não diminuem a necessidade de maior precisão no campo do desenvolvimento econômico, e torna-se também necessário que os economistas adotem lima posição mais modesta no que diz respeito à validade e à generalidade de suas especulações .

O desenvolvimento econômico é parte de um conjunto de processos mais amplo e mais complexo que habitualmente sãc estudados sob a designação de mudança social. $O$ isolamento existente entre o processo de desenvolvimento econômico e o processo de mudança social constitui indiscutivelmente um obstáculo para que se possam atingir generalizações mais válidas. Apesar da posição parecer bastante aceita pela maioria dos eccnomistas contemporânecs, não encontramos muitos trabalhos que adotem a abordagem referida; e a própria inclusão do processo de desenvolvimento econômico, na mais ampla perspectiva da mułança social, não constitui tarefa livre de dificuldades porque ainda é desconhecida no seu funcionamento e portanto imprevisível.

INão adotamos a pcsição de que os economistas devem abandonar o campo e as indagações sôbre o desenvolvimento econômico. Ao contrário, insistiriamos que devem 
ter sempre presente os problemas do desenvolvimento, entretantc ao mesmo tempo busquem uma metodologia mais psecisa e adequada ao objeto de suas especulações. Se esta sugestão é limitativa aos objetivos das generalizações, por outro lado ela representaria um processo real pela obtenção de maior precisão. A escolha entre generalidade e precisão é uma imposição (não desejada) para qualquer ciência nova. 